\title{
The effect of breast parenchymal density on breast cancer subtypes and prognostic factors
}

\author{
Cemil Yüksel', Serdar Çulcu', Batuhan Bakırarar², Lütfi Doğan'
}

${ }^{1}$ Ankara Abdurrahman Yurtaslan Oncology Training and Research Hospital, University of Health Science, Ankara, Turkey
2Department of Biostatistics, Faculty of Medicine, Ankara University, Ankara, Turkey
Corresponding Author: Cemil Yüksel (E-mail: cemil8537@hotmail.com)

\section{Abstract}

Objective: Mammographic breast parenchymal density is the radiological composition of radiodense fibroglandular tissue and radiolucent adipose tissue. Dense breasts restrict the imaging of lesions detected by mammography and reduce the sensitivity of mammography. In this study, we investigated correlation between breast parenchymal density and prognosis, tumor biology, reoperation rates, and prognostic factors.

Methods: Patients who were operated for breast cancer between January 2017 and December 2019 were included. The craniocaudal and mediolateral images obtained during conventional mammograms were collected in a database. The appearance of radiologically dense and lucent areas on mammography was taken as the mammographic percentage consistent with the current literature

Results: According to breast parenchymal density, there were 21 patients (14.7\%) with type 1 breast density, 29 (20.3\%) with type 2, 47 (32.9\%) with type 3, and 46 (32.1\%) with type 4. Mean survival time due to breast cancer was $27.45 \pm 17.85$ months (1-63), and 139 patients (97.2\%) lived, while 4 (2.8\%) were exitus.

Conclusion: Increased breast parenchymal density is a crucial risk factor for breast cancer. The effects of density on tumor biology and prognosis are still controversial. Although increased breast density seems to have an effect on indicators of poor prognosis. Additional examinations should be taken into consideration in order not to cause delay or skipping in diagnosis due to the decreased sensitivity of mammography in dense breasts

Keywords: Breast Cancer, Parenchymal Density, Prognosis, Mammography

\section{Introduction}

In women aged over 40 years, mammography is the first preferred imaging method for breast cancer screening and has been the only one shown to reduce cancer mortality. ${ }^{1}$ Breast density is associated with collagen, epithelial, and stromal tissues. The interstitium and breast gland tissue are less radiolucent than adipose tissue. Mammographic breast parenchymal density is the radiological composition of radiodense fibroglandular tissue and radiolucent adipose tissue. Advanced age, high body mass index (BMI), number of births, breastfeeding time, and antiestrogens in breast tissue such as Tamoxifen cause a decrease in breast density, while hormone replacement therapy and use of oral contraceptives cause an increase. ${ }^{2}$ Recently, the American College of Radiology has recommended the assessment of breast density in the BIRADS (Breast Imaging Reporting and Data System) system for the evaluation of lesions in terms of malignancy risk. ${ }^{3}$

Dense breasts restrict the imaging of lesions detected by mammography and reduce the sensitivity of mammography. Mammography has been reported to have a sensitivity of $87 \%$ and a specificity of $97 \%$ in adipose breast tissue (Type 1 or Type A) and a sensitivity of $63 \%$ and a specificity of $89 \%$ in high density (Type 4 or Type D) breast. ${ }^{4}$

MBD is a dynamic process that differs with age and reproductive changes. Therefore, the correlation between MBD and tumor biology and prognosis has been the subject of our study. ${ }^{5-7}$

In this study, we investigated correlation between breast parenchymal density and prognosis, tumor biology, reoperation rates, and prognostic factors. With the changing life habits and nutrition habits and the new diagnosis and treatment modalities, it is crucial for this correlation to be examined now.

\section{Materials and Methods}

Patients who were operated for breast cancer between January 2017 and December 2019 were included. Patients'surgery and pathology reports, hormone receptor status, preoperative hematological and biochemical parameters, demographic characteristics, and overall survival rates were analyzed retrospectively on an electronic environment. Approval was obtained from the ethics committee of our hospital. 143 patients were included. Patients who did not receive neoadjuvant therapy, who had no history of hormone replacement therapy or oral contraceptive use, and who were evaluated for breast parenchymal density in their preoperative mammography were included. Inoperable breast cancer patients were excluded.

The demographic data of the groups (age, BMI, etc.), their postoperative pathological data (TM characteristics) and other radiological evaluations (USG MRI. Is there any data on this?) were recorded.

Hormone receptor status was recorded according to the pathology report for human epidermal growth factor receptor 2 (HER-2) expression. Histological grade was recorded according to the Scarff-Bloom-Richardson grading system. Lymphovascular invasion status was recorded according to lymphatic or vascular status indicated in the pathology reports.

\section{Evaluation of density}

The craniocaudal and mediolateral images obtained during conventional mammograms were collected in a database. The appearance of radiologically dense and lucent areas on mammography was taken as the mammographic percentage 
consistent with the current literature. ${ }^{8}$ In the evaluation of density, the average density of both breasts was taken. The percentage of the area filled by radiologically dense breast tissue was analyzed and then divided into six different percentile categories according to the Boyd cutoff value $(<5 \%, 5 \%-10 \%$, $10 \%-25 \%, 25 \%-50 \%, 5 \%-75 \%$, or $>75 \%) .{ }^{24}$ Defined by Boyd et al., this categorization includes four types to categorize the mammographic density percentages ${ }^{9}$ (Type $\mathrm{I}-<25 \%$; Type II-25\%-50\%; Type III-51\%-75\%; Type IV->75\%). We used this categorization in the current study. The patients were divided into four groups according to their breast parenchymal densities.

\section{Statistical analysis}

The SPSS 11.5 software was used in the analysis of the data. In descriptive statistics, quantitative variables are given as mean \pm standard deviation and median (minimum-maximum), and qualitative variables are given as number of patients (percentage). Whether there was a difference between more than two categories of a qualitative variable according to a quantitative variable was analyzed using the OneWay ANOVA test if normal distribution assumptions were provided and the Kruskal-Wallis-H test if not. The Chi-squared test and Fisher's exact test were used to compare two qualitative variables. $\mathrm{p}<0.05$ was considered as the statistical significance level.

\section{Results}

A total of 143 patients were included. The mean \pm standard deviation and median values for patients' ages were found to be $61.36 \pm 11.54$ and 61.00 (33.00-89.00), respectively. According to breast parenchymal density, there were 21 patients $(14.7 \%)$ with type 1 breast density, 29 (20.3\%) with type 2, 47 (32.9\%) with type 3 , and 46 (32.1\%) with type 4.58 were Grade $0-1$ (40.6\%), 64 were Grade 2 (44.7\%), and 21 were Grade 3 (14.7\%). Similarly, 97 patients were node-negative, while 46 were node-positive. 47 (32.8\%) of the patients received breast-conserving surgery (BCS), 25 received simple mastectomy $(17.4 \%), 44(30.7 \%)$ received modified radical mastectomy (MRM), 8 (5.6\%) received mastectomy upon having positive surgical margin after BCS and axillary dissection (AD), $15(10.5 \%)$ received resection after $\mathrm{BCS}, 3(2.1 \%)$ received $\mathrm{BCS}+\mathrm{AD}$, and $1(0.9 \%)$ received bilateral mastectomy. There was no statistically significant correlation between breast parenchymal density and survival $(p=0.105)$.

There was no statistically significant correlation between operation type and survival $(p>0.005)$. Mean survival time due to breast cancer was $27.45 \pm 17.85$ months (1-63), and 139 patients (97.2\%) lived, while 4 (2.8\%) were exitus. Descriptive variables are given in Table 1.

Regarding the correlation between patients' demographic, histopathological, and clinicopathological characteristics and their breast parenchymal density, the correlations between breast parenchymal density and lymph node status, grade, HER-2 expression, surgical margin positivity, and survival were not statistically significant. The $\mathrm{p}$ values were 0.129 $0.152-0.569-0.876-0.105$, respectively. Estrogen and progesterone receptor positivity decrease with increased breast density, which was statistically significant $(p=0.001 / p=0.039)$.
Comparing lymphovascular invasion and breast parenchymal density, we observed that the rate of lymphovascular invasion increased with increased density, which was statistically significant ( $p=0.002)$. 38 patients were luminal A, 26 were HER-2 positive luminal B, 53 were luminal B, 17 were triple negative and 9 were HER-2 positive, and there was a statistically significant correlation between breast parenchymal density and cancer subtype ( $p=0.011) .14$ patients were Grade 1, 58 were Grade 2 and 71 were Grade 3, and the grade increased with increased breast parenchymal density, which was statistically significant $(p<0.001)$. It was observed that there was an increase in in the examinations performed, particularly in MRI, with increased breast parenchymal density, which was statistically significant $(p=0.09)$. (Table 2)

Comparing the quantitative variables and breast parenchymal density, we found no statistically significant correlation with survival time $(p=0.917)$. Although the number of positive lymph nodes was found to be the highest in patients with type 4 breast parenchyma, the difference was not statistically significant $(p=0.132)$. The decrease in age with the increase in breast parenchymal density was statistically significant $(p<0.001)$. Tumor size was statistically significantly the largest in patients with type 4 breast parenchyma at a mean of $3.38 \mathrm{~cm}(p=0.012)$. Mean Ki67 expression was $32.8 \%$, and the highest Ki67 expression was found in type 4 breast parenchyma patients at $46.24 \%$, which was statistically significant $(p<0.001)$. (Table 3)

\section{Discussion}

Density is revealed on mammography by measuring the content of fibroglandular tissue. Recent research tries to explain the correlation between breast cancer and breast density, but this is made difficult by the lack of standardization for the measurement of breast density. The histopathological type and grade of a tumor determines its prognosis and aggression. ${ }^{10}$ Thus, we investigated the correlation between breast density and prognosis, age, tumor size, stage, hormone receptors, HER-2 status, grade, lymphovascular invasion, surgical margin status, reoperation, and additional examinations.

Increased breast density is a very important risk factor for breast cancer in premenopausal and young women. Increased breast density also reduces the sensitivity of MG. ${ }^{11-13}$ Previous research has reported that MMG sensitivity ranges from $100 \%$ to $45 \%$ between fatty breasts and dense breast. ${ }^{14}$ This may result in delayed diagnosis and increase the need for additional examination. In fact, parenchymal density had no effect on stage in our study ( $p=0.152)$, but it caused a statistically significant increase in required additional examinations $(p=0.009)$. We believe that MRI in addition to mammography can be very helpful in diagnosis.

There have been numerous studies on breast parenchymal density and its effects on risk of developing breast cancer and prognosis. Wolfe et al. (1976) divided mammographic breast parenchymal density findings into 4 groups for the first time and reported that breast density was a risk factor for the development of breast cancer. ${ }^{15,16}$ In a meta-analysis including 42 studies, McCormack et al. demonstrated a strong correlation between risk of breast cancer and breast parenchymal density. ${ }^{17}$ Breast density is associated with collagen, epithelial, and 


\begin{tabular}{|c|c|c|}
\hline Variables & & \\
\hline \multirow{2}{*}{ Age } & Mean $\pm S D$ & $61.36 \pm 11.54$ \\
\hline & Median (Min.-Max.) & $61.00(33.00-89.00)$ \\
\hline \multirow{4}{*}{ Breast parenchyma, n (\%) } & 1 & $21(14.7)$ \\
\hline & 2 & $29(20.3)$ \\
\hline & 3 & $47(32.9)$ \\
\hline & 4 & $46(32.1)$ \\
\hline \multirow{2}{*}{ Lymph node, n (\%) } & Negative & $97(67.8)$ \\
\hline & Positive & $46(32.2)$ \\
\hline \multirow{3}{*}{ Grade, n (\%) } & $0-1$ & $58(40.6)$ \\
\hline & 2 & $64(44.7)$ \\
\hline & 3 & $21(14.7)$ \\
\hline \multirow{2}{*}{ ER, n (\%) } & Positive & $117(81.8)$ \\
\hline & Negative & $26(18.2)$ \\
\hline \multirow{2}{*}{ PR, n (\%) } & Positive & $109(76.2)$ \\
\hline & Negative & $34(23.8)$ \\
\hline \multirow{2}{*}{ Cerb2 status, n (\%) } & Positive & $35(24.5)$ \\
\hline & Negative & $108(75.5)$ \\
\hline \multirow{5}{*}{ Type, n (\%) } & Luminal A & $38(26.6)$ \\
\hline & Luminal B HER-2 & $26(18.2)$ \\
\hline & Triple Negative & $17(11.9)$ \\
\hline & Luminal B & $53(37.0)$ \\
\hline & HER-2 Positive & $9(6.3)$ \\
\hline \multirow{2}{*}{ LVI, n (\%) } & Yes & $35(24.5)$ \\
\hline & No & $108(75.5)$ \\
\hline \multirow{3}{*}{ Grade, n (\%) } & 1 & $14(9.8)$ \\
\hline & 2 & $58(40.6)$ \\
\hline & 3 & $71(49.6)$ \\
\hline \multirow{2}{*}{ Survival, n (\%) } & Ex & $4(2.8)$ \\
\hline & Alive & $139(97.2)$ \\
\hline \multirow{2}{*}{ Survival time } & Mean \pm SD & $27.45 \pm 17.85$ \\
\hline & Median (Min.-Max.) & $24.00(1.00-63.00)$ \\
\hline \multirow{2}{*}{ Ki67 } & Mean $\pm S D$ & $32.83 \pm 26.45$ \\
\hline & Median (Min.-Max.) & $22.00(2.00-95.00)$ \\
\hline
\end{tabular}

stromal tissues. Increased epithelial and fibroblast activity can contribute to increased breast density and breast cancer development. ${ }^{18,19}$

A meta-analysis by Petterson et al. (2014) including three studies showed that breast parenchymal density increased the risk of developing breast cancer regardless of the menopausal status. ${ }^{20}$ Research shows that the risk of developing cancer is 4-6 times higher compared in dense breasts compared to fatty breasts. ${ }^{21,22}$ Pre- and postmenopausal estrogen receptor positive patients whose breast density showed a higher decrease with tamoxifen have been shown to have better prognosis. ${ }^{7,23}$

Studies on breast density and breast cancer prognosis are yet to reach a consensus on the matter. There is research suggesting fatty breast density to indicate poor prognosis, 5,6 while there is also research suggesting the opposite. ${ }^{24,25}$ In addition, there are also studies arguing that breast density has no correlation to prognosis. ${ }^{11,26}$ We found that increased 


\begin{tabular}{|c|c|c|c|c|c|c|c|c|c|c|}
\hline & & \multicolumn{9}{|c|}{ Breast parenchyma } \\
\hline \multicolumn{2}{|c|}{ Variables } & \multicolumn{2}{|c|}{1} & \multicolumn{2}{|c|}{2} & \multicolumn{2}{|c|}{3} & \multicolumn{2}{|c|}{4} & \multirow[b]{2}{*}{$p$ value } \\
\hline & & Number & $\%$ & Number & $\%$ & Number & $\%$ & Number & $\%$ & \\
\hline \multirow{3}{*}{ Lymph Node } & Negative & 11 & 52.4 & 24 & 82.8 & 30 & 63.8 & 32 & 69.6 & \multirow{2}{*}{$0.129^{\mathrm{a}}$} \\
\hline & Positive & 10 & 47.6 & 5 & 17.2 & 17 & 36.2 & 14 & 30.4 & \\
\hline & $0-1$ & 6 & 28.6 & 18 & 62.1 & 19 & 40.4 & 15 & 32.6 & \multirow{3}{*}{$0.152^{b}$} \\
\hline \multirow[t]{2}{*}{ Grade } & 2 & 11 & 52.4 & 10 & 34.5 & 20 & 42.6 & 23 & 50.0 & \\
\hline & 3 & 4 & 19.0 & 1 & 3.4 & 8 & 17.0 & 8 & 17.4 & \\
\hline \multirow{2}{*}{ ER } & Positive & 21 & 100.0 & 27 & 93.1 & 39 & 83.0 & 30 & 65.2 & \multirow{2}{*}{$0.001^{\mathrm{a}}$} \\
\hline & Negative & 0 & 0.0 & 2 & 6.9 & 8 & 17.0 & 16 & 34.8 & \\
\hline \multirow{2}{*}{ PR } & Positive & 19 & 90.5 & 25 & 86.2 & 36 & 76.6 & 29 & 63.0 & \multirow{2}{*}{$0.039^{a}$} \\
\hline & Negative & 2 & 9.5 & 4 & 13.8 & 11 & 23.4 & 17 & 37.0 & \\
\hline \multirow{2}{*}{ Cerb2 status } & Positive & 3 & 14.3 & 6 & 20.7 & 13 & 27.7 & 13 & 28.3 & \multirow{2}{*}{$0.569^{\mathrm{a}}$} \\
\hline & Negative & 18 & 85.7 & 23 & 79.3 & 34 & 72.3 & 33 & 71.7 & \\
\hline \multirow{5}{*}{ Type } & Luminal A & 10 & 47.6 & 12 & 41.5 & 11 & 23.4 & 5 & 10.8 & \multirow{5}{*}{$0.011^{\mathrm{b}}$} \\
\hline & Luminal B HER-2 & 3 & 14.3 & 5 & 17.2 & 9 & 19.1 & 9 & 19.6 & \\
\hline & Triple Negative & 0 & 0.0 & 1 & 3.4 & 4 & 8.5 & 12 & 26.1 & \\
\hline & Luminal B & 8 & 38.1 & 10 & 34.5 & 19 & 40.5 & 16 & 34.8 & \\
\hline & HER-2 Positive & 0 & 0.0 & 1 & 3.4 & 4 & 8.5 & 4 & 8.7 & \\
\hline \multirow{2}{*}{ LVI } & Yes & 2 & 9.5 & 3 & 10.3 & 10 & 21.3 & 20 & 43.5 & \multirow{2}{*}{$0.002^{\mathrm{a}}$} \\
\hline & No & 19 & 90.5 & 26 & 89.7 & 37 & 78.7 & 26 & 56.5 & \\
\hline \multirow{3}{*}{ Grade } & 1 & 2 & 9.5 & 3 & 10.3 & 5 & 10.6 & 4 & 8.7 & \multirow{3}{*}{$<0.001^{b}$} \\
\hline & 2 & 13 & 61.9 & 18 & 62.1 & 19 & 40.5 & 8 & 17.4 & \\
\hline & 3 & 6 & 28.6 & 8 & 27.6 & 23 & 48.9 & 34 & 73.9 & \\
\hline \multirow{2}{*}{$\begin{array}{l}\text { Surgical } \\
\text { margin }\end{array}$} & Suvival & 17 & 81.0 & 24 & 82.8 & 41 & 87.2 & 38 & 82.6 & \multirow{2}{*}{$0.876^{b}$} \\
\hline & Positive & 4 & 19.0 & 5 & 17.2 & 6 & 12.8 & 8 & 17.4 & \\
\hline \multirow{2}{*}{$\begin{array}{l}\text { Additional } \\
\text { examination }\end{array}$} & Yes & 4 & 19.0 & 6 & 20.7 & 14 & 29.8 & 24 & 52.2 & \multirow{2}{*}{$0.009^{\mathrm{a}}$} \\
\hline & No & 17 & 81.0 & 23 & 79.3 & 33 & 70.2 & 22 & 47.8 & \\
\hline \multirow{2}{*}{ Survival } & Ex & 2 & 9.5 & 1 & 3.4 & 0 & 0.0 & 1 & 2.2 & \multirow{2}{*}{$0.105^{b}$} \\
\hline & Alive & 19 & 90.5 & 28 & 96.6 & 47 & 100.0 & 45 & 97.8 & \\
\hline
\end{tabular}

a:Chi-squared test, b:Fisher's exact test

breast parenchymal density had no effect on prognosis, but our short follow-up period was an important factor in the lack of effective evaluation of prognosis. Of course, these findings are not homogeneous, as there is still no standardization for breast density. We think that more consistent findings can be obtained once standardization increases.

Similar to the effect of parenchymal density on prognosis, studies on breast parenchymal density and tumor biology have not yet reached a consensus. There is research that found no correlation between breast parenchymal density and hormone receptor positivity, ${ }^{27,} 28$ while two recent studies have shown that patients with higher breast parenchymal density had higher ER positivity. ${ }^{29,}{ }^{30}$ Yaghjyan et al. found a strong correlation between breast parenchymal density and ER positivity and concluded that density had no effect on HER-2 status. $^{31}$ They also demonstrated that parenchymal density had no effect on lymph node positivity. In our study, estrogen and progesterone receptor positivity were found to be increased, particularly in fatty breasts $(p=0.129)$, and HER-2 receptor positivity was observed to be more frequent in dense breasts, which was statistically significant $(p=0.569)$.

Triple negative breast cancers have a pattern of gene expression that shows a course of overexpression of genes responsible for cell proliferation and DNA replication pathways regulated by cyclin-dependent kinase inhibitor 1A (CDKN1A). HER-2 positive breast cancers show an overexpression of genes 


\begin{tabular}{|c|c|c|c|c|c|c|c|c|c|}
\hline \multirow{3}{*}{ Variables } & \multicolumn{8}{|c|}{ Breast Parenchyma } & \multirow[b]{3}{*}{ pvalue } \\
\hline & \multicolumn{2}{|l|}{1} & \multicolumn{2}{|l|}{2} & \multicolumn{2}{|c|}{3} & \multicolumn{2}{|l|}{4} & \\
\hline & Mean $\pm S D$ & $\begin{array}{l}\text { Median } \\
\text { (Min.-Max.) }\end{array}$ & Mean \pm SD & $\begin{array}{l}\text { Median } \\
\text { (Min.-Max.) }\end{array}$ & Mean \pm SD & $\begin{array}{l}\text { Median } \\
\text { (Min.-Max.) }\end{array}$ & Mean \pm SD & $\begin{array}{l}\text { Median } \\
\text { (Min.-Max.) }\end{array}$ & \\
\hline Age & $66.33 \pm 10.80$ & $\begin{array}{l}67.00 \\
(40.00-85.00)\end{array}$ & $60.72 \pm 8.59$ & $\begin{array}{l}62.00 \\
(41.00-75.00)\end{array}$ & $57.06 \pm 10.25$ & $\begin{array}{l}56.00 \\
(36.00-80.00)\end{array}$ & $43.20 \pm 9.17$ & $\begin{array}{l}41.50 \\
(26.00-69.00)\end{array}$ & $<0.001^{\mathrm{a}}$ \\
\hline Tumor Size & $3.15 \pm 1.91$ & $\begin{array}{l}2.50 \\
(0.50-8.00)\end{array}$ & $1.93 \pm 1.10$ & $\begin{array}{l}1.80 \\
(0.20-4.50)\end{array}$ & $2.65 \pm 1.48$ & $\begin{array}{l}2.10 \\
(0.30-7.50)\end{array}$ & $3.38 \pm 2.20$ & $\begin{array}{l}2.70 \\
(0.80-11.00)\end{array}$ & $0.012^{b}$ \\
\hline $\begin{array}{l}\text { Number } \\
\text { of Positive } \\
\text { Lymph } \\
\text { nodes }\end{array}$ & $1.48 \pm 2.58$ & $\begin{array}{l}0.00 \\
(0.00-9.00)\end{array}$ & $1.10 \pm 5.19$ & $\begin{array}{l}0.00 \\
(0.00-28.00)\end{array}$ & $1.36 \pm 2.92$ & $\begin{array}{l}0.00 \\
(0.00-13.00)\end{array}$ & $1.54 \pm 4.25$ & $\begin{array}{l}0.00 \\
(0.00-24.00)\end{array}$ & $0.132^{b}$ \\
\hline Ki67 status & $20.57 \pm 21.44$ & $\begin{array}{l}15.00 \\
(3.00-80.00)\end{array}$ & $20.86 \pm 21.24$ & $\begin{array}{l}15.00 \\
(2.00-90.00)\end{array}$ & $32.55 \pm 24.00$ & $\begin{array}{l}25.00 \\
(2.00-80.00)\end{array}$ & $46.24 \pm 28.05$ & $\begin{array}{l}50.00 \\
(5.00-95.00)\end{array}$ & $<0.001^{b}$ \\
\hline $\begin{array}{l}\text { Survival } \\
\text { time }\end{array}$ & $28.62 \pm 16.48$ & $\begin{array}{l}27.00 \\
(7.00-63.00)\end{array}$ & $27.14 \pm 19.16$ & $\begin{array}{l}22.00 \\
(7.00-63.00)\end{array}$ & $27.38 \pm 17.47$ & $\begin{array}{l}24.00 \\
(8.00-63.00)\end{array}$ & $27.17 \pm 18.53$ & $\begin{array}{l}24.00 \\
(1.00-63.00)\end{array}$ & $0.917^{b}$ \\
\hline
\end{tabular}

a:OneWay ANOVA, b:Kruskal-Wallis-H test

responsible for HER-2 pathways. Epidemiological studies have shown that risk factors for reproduction such as birth information or age of menarche and body mass index are associated with ER or PR negative tumors rather than with ER or PR positive tumors. ER negative breast cancers, especially triple negative breast cancers, are diagnosed at an earlier age. ${ }^{32-34}$ Mema et al. showed that patients with low breast density had a 2.53 times higher risk of developing triple negative breast cancer. ${ }^{35}$ In our study, patients with dense breasts showed higher triple negativity, which was statistically significant $(p=0.011)$.

Since density may cause a skipping of possible lesions in breast screening mammograms, some studies have shown increased breast parenchymal density to be associated with larger tumor size, higher number of lymph nodes, and advanced stage. ${ }^{36,37}$ In our study, increased breast density was found to be associated with increased tumor size $(p=0.012)$ but not with pathological stage. Another study found patients with fatty breasts to be associated with lower stage independently of hormonotherapy and that patients with dense breast parenchyma were at an advanced stage. ${ }^{38}$ This may be associated with difficulty in diagnosis in dense breasts and with low mammographic sensitivity.

Lymphovascular invasion is when cancer cells infiltrate the blood vessels or lymphatic vessels inside or around the tumor. LVI is thought to mediate cancer dissemination, ${ }^{39,40}$ and is accompanied by poor prognosis and pathological characteristics. ${ }^{41,42}$ In our study, lymphovascular invasion positivity was found to be increased with increased density $(p=0.002)$. Due to our short follow-up period, we could not evaluate the effect of lymphovascular invasion positivity on prognosis.

The limitations of this study were its retrospective nature, the low number of patients, the lack of evaluation of factors affecting prognosis (e.g., additional disease, etc.), short follow-up period, and the lack of evaluation of adjuvant treatment conditions.

\section{Conclusion}

Increased breast parenchymal density is a crucial risk factor for breast cancer. The effects of density on tumor biology and prognosis are still controversial. Although increased breast density seems to have an effect on indicators of poor prognosis, such as LVI and tumor grade, its effect on prognosis could not be shown. In addition, additional examinations should be taken into consideration in order not to cause delay or skipping in diagnosis due to the decreased sensitivity of mammography in dense breasts.

\section{Disclosure Statement:}

There is no conflict of interest in writing of this article.

No financial support or funding has been received.

\section{Declarations}

Ethics approval and consent to participate: This retrospective study was reviewed and approved by the Ethics Committee of Health Science of University Ankara Abdurrahman Yurtaslan Oncology Training and Research Hospital.

Availability of data and materials: The datasets used and/or analyzed during the current study are available from the corresponding author on reasonable request.

Funding: There is no funding for this study. 


\section{References}

1. Smith RA, Duffy SW, Gabe R, Tabar L, Yen AM, Chen TH. The randomized trials of breast cancer screening: What have we learned? Radiol Clinics. 2004;42(5):793-806

2. Huo C, Chew G, Britt K, Ingman W, Henderson M, Hopper J, et al. Mammographic density_-a review on the current understanding of its association with breast cancer. Breast Cancer Res Treatment 2014;144(3):479-502

3. Sickles EA, D'Orsi CJ, Bassett LW, Appleton CM, Berg WA, Burnside ES. ACR BI-RADS ${ }^{\circledR}$ Atlas, Breast Imaging Reporting and Data System. Reston, VA: American College of Radiology. 2013:39-48.

4. Carney PA, Miglioretti DL, Yankaskas BC, Kerlikowske K, Rosenberg R, Rutter CM, et al. Individual and combined effects of age, breast density, and hormone replacement therapy use on the accuracy of screening mammography. Ann Intern Med. 2003;138(3):168-75.

5. Masarwah A, Auvinen P, Sudah M, Dabravolskaite V, Arponen O, Sutela A, et al. Prognostic contribution of mammographic breast density and HER2 overexpression to the Nottingham Prognostic Index in patients with invasive breast cancer. BMC Cancer. 2016;16(1):833.

6. Elsamany S, Alzahrani A, Elkhalik SA, Elemam O, Rawah E, Farooq MU, et al. Prognostic value of mammographic breast density in patients with metastatic breast cancer. Med Oncol. 2014;31(8):96

7. Masarwah A, Auvinen P, Sudah M, Rautiainen S, Sutela A, Pelkonen O, et al. Very low mammographic breast density predicts poorer outcome in patients with invasive breast cancer. Eur Radiol. 2015;25(7):1875-82.

8. Boyd NF, Martin LJ, Yaffe MJ, Minkin S. Mammographic density and breast cancer risk: Current understanding and future prospects. Breast Cancer Res. 2011;13(6):223

9. Boyd N, O'sullivan B, Campbell J, Fishell E, Simor I, Cooke G, et al. Mammographic signs as risk factors for breast cancer. Br J Cancer. 1982:45(2):185-93.

10. Song T, Wang Y, Du W, Cao S, Tian Y, Liang Y. The method for breast cancer grade prediction and pathway analysis based on improved multiple kerne learning. J Bioinform Computat Biol. 2017;15(01):1650037.

11. Ginsburg O, Martin L, Boyd N. Mammographic density, lobular involution, and risk of breast cancer. Br J Cancer. 2008;99(9):1369-74.

12. Sprague BL, Gangnon RE, Burt V, Trentham-Dietz A, Hampton JM, Wellman $\mathrm{RD}$, et al. Prevalence of mammographically dense breasts in the United States. JNCI J Natl Cancer Inst. 2014:106(10)

13. Kolb TM, Lichy J, Newhouse JH. Comparison of the performance of screening mammography, physical examination, and breast US and evaluation of factors that influence them: an analysis of 27,825 patient evaluations. Radiology. 2002;225(1):165-75.

14. Berg WA, Gutierrez L, NessAiver MS, Carter WB, Bhargavan M, Lewis RS, et al. Diagnostic accuracy of mammography, clinical examination, US, and MR imaging in preoperative assessment of breast cancer. Radiology. 2004; 233(3):830-49.

15. Wolfe JN. Breast patterns as an index of risk for developing breast cancer. Am J Roentgenol. 1976;126(6):1130-7

16. Wolfe JN. Risk for breast cancer development determined by mammographic parenchymal pattern. Cancer. 1976;37(5):2486-92.

17. McCormack VA, dos Santos Silva I. Breast density and parenchymal patterns as markers of breast cancer risk: a meta-analysis. Cancer Epidemiol Prev Biomarkers. 2006;15(6):1159-69.

18. Guo Y-P, Martin L, Hanna W, Banerjee D, Miller N, Fishell E, et al. Growth factors and stromal matrix proteins associated with mammographic densities. Cancer Epidemiol Prev Biomarkers. 2001;10(3):243-8.

19. Li T, Sun L, Miller N, Nicklee T, Woo J, Hulse-Smith L, et al. The association of measured breast tissue characteristics with mammographic density and other risk factors for breast cancer. Cancer Epidemiol Prev Biomarkers. 2005;14(2):343-9.

20. Pettersson A, Graff RE, Ursin G, dos Santos Silva I, McCormackV, Baglietto L, et al. Mammographic density phenotypes and risk of breast cancer: A metaanalysis. J Natl Cancer Inst. 2014;106(5):dju078.

21. Boyd NF, Guo H, Martin LJ, Sun L, Stone J, Fishell E, et al. Mammographic density and the risk and detection of breast cancer. New Engl J Med. 2007:356(3):227-36.
22. Nyante SJ, Sherman ME, Pfeiffer RM, Berrington de Gonzalez A, Brinton LA, Aiello Bowles EJ, et al. Prognostic significance of mammographic density change after initiation of tamoxifen for ER-positive breast cancer. JNCI J Natl Cancer Inst. 2015;107(3)

23. Li J, Humphreys K, Eriksson L, Edgren G, Czene K, Hall P. Mammographic density reduction is a prognostic marker of response to adjuvant tamoxifen therapy in postmenopausal patients with breast cancer. J Clin Oncol. 2013;31(18):2249.

24. Chiu SY-H, Duffy S, Yen AM-F, Tabár L, Smith RA, Chen H-H. Effect of baseline breast density on breast cancer incidence, stage, mortality, and screening parameters: 25-year follow-up of a Swedish mammographic screening. Cancer Epidemiol Prev Biomarkers. 2010;19(5):1219-28.

25. Gierach GL, Ichikawa L, Kerlikowske K, Brinton LA, Farhat GN, Vacek PM, et al. Relationship between mammographic density and breast cancer death in the Breast Cancer Surveillance Consortium. J Natl Cancer Inst. 2012;104(16):1218-27.

26. Maskarinec G, Pagano IS, Little MA, Conroy SM, Park S-Y, Kolonel LN Mammographic density as a predictor of breast cancer survival: The Multiethnic Cohort. Breast Cancer Res. 2013;15(1):R7.

27. Chen J-H, Hsu F-T, Shih H-N, Hsu C-C, Chang D, Nie K, et al. Does breast density show difference in patients with estrogen receptor-positive and estrogen receptor-negative breast cancer measured on MRI? Ann Oncol. 2009;20(8):1447-9.

28. Yang W-T, Dryden M, Broglio K, Gilcrease M, Dawood S, Dempsey PJ, et al. Mammographic features of triple receptor-negative primary breast cancers in young premenopausal women. Breast Cancer Res Treatment. 2008;111(3):405-10

29. Conroy SM, Pagano I, Kolonel LN, Maskarinec G. Mammographic density and hormone receptor expression in breast cancer: The Multiethnic Cohort Study. Cancer Epidemiol. 2011;35(5):448-52.

30. J.Ding JWR, Girling A, Thompson D, Easton D. . Mammographic density, estrogen receptor status and other breast cancer tumor characteristics. Breast J. 2010;16(3):279-89.

31. K.Ghosh K BK, Sellers T, et al. . Association of mammographic density with the pathology of subsequent breast cancer among postmenopausal women. Cancer Epidemiol Biomarkers Prev. 2008;17(4):872-9.

32. T. FS. Molecular portraits of breast cancer: Tumour subtypes as distinct disease entities. Eur J Cancer. 2004:40(18):2667-75.

33. Ma HWY, Sullivan-Halley J, et al. Use of four biomarkers to evaluate the risk of breast cancer subtypes in the women's contraceptive and reproductive experiences study. Cancer Res. 2010;70(2):575-87.

34. Yang X C-CJ, Goode E, et al. 2011;103(3): 250-263. . Associations of breast cancer risk factors with tumor subtypes: A pooled analysis from the Breast Cancer Association Consortium Studies. J Natl Cancer Inst. 2011;103(3):250-63.

35. Mema E SF, Chun J, Kaplowitz E, Price A, Goodgal J, Moy L. The relationship of breast density in mammography and magnetic resonance imaging in women with triple negative breast cancer. Eur J Radiol. 2020;124

36. Porter GEA, Cornford E, et al.. 2007;188(3):676-683. . Influence of mammographic paren- chymal pattern in screening-detected and interval invasive breast cancers on pathologic features, mammographic features, and patient survival. AJR Am J Roentgenol.188(3):676-83.

37. M.Sala E SL, Warren R, et al. . Size, node status and grade of breast tumours: association with mammographic parenchymal patterns. Eur Radiol. 2000;10(1):157-61.

38. Kerlikowske K, Cook AJ, Buist DS, Cummings SR, Vachon C, Vacek P, et al. Breast cancer risk by breast density, menopause, and postmenopausa hormone therapy use. J Clin Oncol. 2010;28(24):3830.

39. Ma Q, Dieterich LC, Detmar M. Multiple roles of lymphatic vessels in tumor progression. Curr Opin Immunol. 2018;53:7-12.

40. Zhang S ZD, Gong M, Wen L, Liao C, Zou L High lymphatic vessel density and presence of lymphovascular inva- sion both predict poor prognosis in breast cancer. BMC Cancer 2017;17(1):335.

41. Rakha EA MS, Lee AH, Morgan D, Pharoah PD, Hodi Z, Macmillan D, Ellis IO. The prognostic significance of lymphovascular invasion in invasive breast carcinoma. Cancer. 2012:3670-80.

42. Zhang ZQ HY, Nian Q, Chen G, Cui SQ, Wang XY Tumor invasiveness, not lymphangiogenesis, is correlated with lymph node metastasis and unfavorable prognosis in young breast cancer patients. PLoS ONE. 2015.

This work is licensed under a Creative Commons Attribution-NonCommercial 3.0 Unported License which allows users to read, copy, distribute and make derivative works for non-commercial purposes from the material, as long as the author of the original work is cited properly. 